\title{
Case Report \\ Sézary Syndrome with CD4/CD8 Double-Negative Neoplastic T Cells in Peripheral Blood
}

\author{
Yuki Kageyama $\mathbb{D}^{1,},{ }^{1,2}$ Kenshiro Tsuda, ${ }^{3}$ Yuma Nato, ${ }^{1}$ Keiki Nagaharu $\mathbb{D}^{2},{ }^{2}$ Kazutaka Suzuki, \\ Akihiko Sawaki, ${ }^{1}$ and Hiroyuki Miyashita ${ }^{1}$ \\ ${ }^{1}$ Department of Hematology, Yokkaichi Municipal Hospital, 2-2-37 Shibata, Yokkaichi 510-8567, Japan \\ ${ }^{2}$ Department of Hematology and Oncology, Mie University Graduate School of Medicine, 2-174 Edobashi, Tsu 514-8507, Japan \\ ${ }^{3}$ Department of Dermatology, Yokkaichi Municipal Hospital, 2-2-37 Shibata, Yokkaichi 510-8567, Japan
}

Correspondence should be addressed to Yuki Kageyama; ykageyama@clin.medic.mie-u.ac.jp

Received 15 January 2021; Revised 30 April 2021; Accepted 19 May 2021; Published 2 June 2021

Academic Editor: Kostas Konstantopoulos

Copyright (c) 2021 Yuki Kageyama et al. This is an open access article distributed under the Creative Commons Attribution License, which permits unrestricted use, distribution, and reproduction in any medium, provided the original work is properly cited.

\begin{abstract}
Sézary syndrome is a rare leukemic type of cutaneous T-cell lymphoma characterized by the presence of neoplastic T cells with cerebriform nuclei (Sézary cells) in the skin, lymph nodes, and peripheral blood. Typical Sézary cells have a CD $3^{+} \mathrm{CD} 4^{+} \mathrm{CD} 8^{-}$ phenotype; however, in cases of the aberrant loss of antigens on Sézary cells, especially the loss of critically important T-cell antigens such as CD4, there is a possibility of misdiagnosing the disease or underestimating the tumor burden of the disease. Here, we report a rare case of Sézary syndrome with CD4/CD8 double-negative Sézary cells in the peripheral blood. Most of the Sézary cells in the peripheral blood had lost CD4 expression, and we diagnosed the disease and evaluated the tumor burden by multicolor flow cytometry. Intriguingly, the Sézary cells showed a typical $\mathrm{CD} 4^{+} \mathrm{CD} 8^{-} \mathrm{CD} 7^{-}$phenotype in the skin even though the cells in the peripheral blood lacked CD4. The patient responded well to treatment with bexarotene and narrow-band ultraviolet B therapy. Analysis by multicolor flow cytometry is essential to diagnose this rare type of Sézary syndrome and evaluate the tumor burden.
\end{abstract}

\section{Introduction}

Sézary syndrome (SS) is a rare leukemic type of cutaneous T-cell lymphoma defined by erythroderma, generalized lymphadenopathy, and the presence of neoplastic $\mathrm{T}$ cells with cerebriform nuclei (Sézary cells) in the skin, lymph nodes, and peripheral blood (PB) [1]. In addition to demonstrating clonally related neoplastic $\mathrm{T}$ cells in the skin and $\mathrm{PB}$, one or more of the following criteria are required to diagnose SS: an absolute Sézary cell count $\geq 1,000 / \mu \mathrm{L}$; an expanded $\mathrm{CD}^{+}{ }^{+} \mathrm{T}$-cell population resulting in a CD4 : CD8 ratio of $\geq 10$; or the loss of one or more $\mathrm{T}$-cell antigens. Because of the morphologic heterogeneity of Sézary cells, flow cytometric analysis of PB is essential for diagnostic purposes and tumor burden monitoring during follow-up $[2,3]$. Typical Sézary cells have a $\mathrm{CD} 3^{+} \mathrm{CD} 4^{+} \mathrm{CD} 8^{-}$phenotype and characteristically lack CD7 and CD26 [4]. In cases with an aberrant loss of CD4 on Sézary cells, it is difficult to diagnose the disease and to evaluate the tumor burden using routine flow cytometric analysis. In this article, we report a rare case of SS with $\mathrm{CD}^{-} \mathrm{CD}^{-}$Sézary cells in $\mathrm{PB}$ detected by multicolor flow cytometry.

\section{Case Presentation}

An 82-year-old woman presented to our hospital because of erythroderma with scattered invasive erythemas, nodules, and tumors on the face, trunk, and extremities (Figure 1). PB analysis revealed a white blood cell count of $14,730 / \mu \mathrm{L}$ (reference range, $3.3-8.6 \times 10^{3} / \mu \mathrm{L}$ ), with $28 \%$ abnormal cells containing cerebriform nuclei (Figure 2), a hemoglobin level of $12.2 \mathrm{~g} / \mathrm{dL}(11.6-14.8 \mathrm{~g} / \mathrm{dL})$, and a platelet count of $311 \times 10^{3} / \mu \mathrm{L}\left(158-348 \times 10^{3} / \mu \mathrm{L}\right)$. The blood levels of lactate dehydrogenase and soluble interleukin-2 receptor were 362 IU/L (124-224 IU/L) and 2,139 U/mL (122-496 U/mL), respectively. A serologic test for human $\mathrm{T}$-cell leukemia 


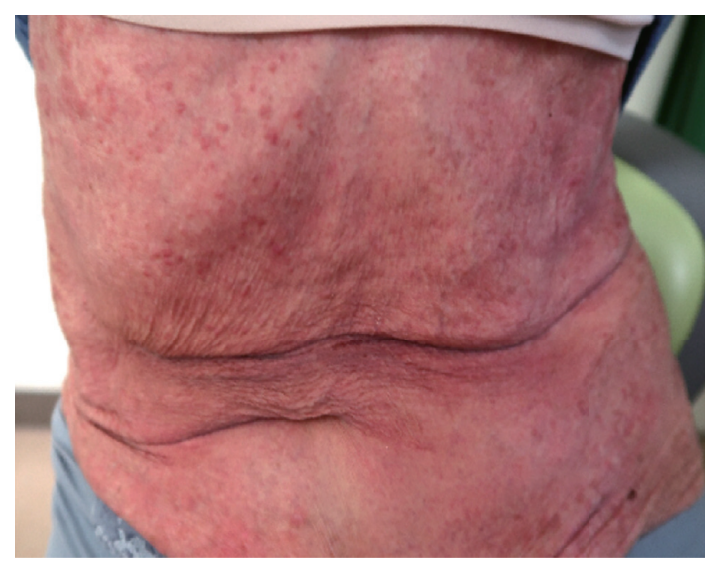

Figure 1: Image of the patient's chest and abdomen with erythroderma.

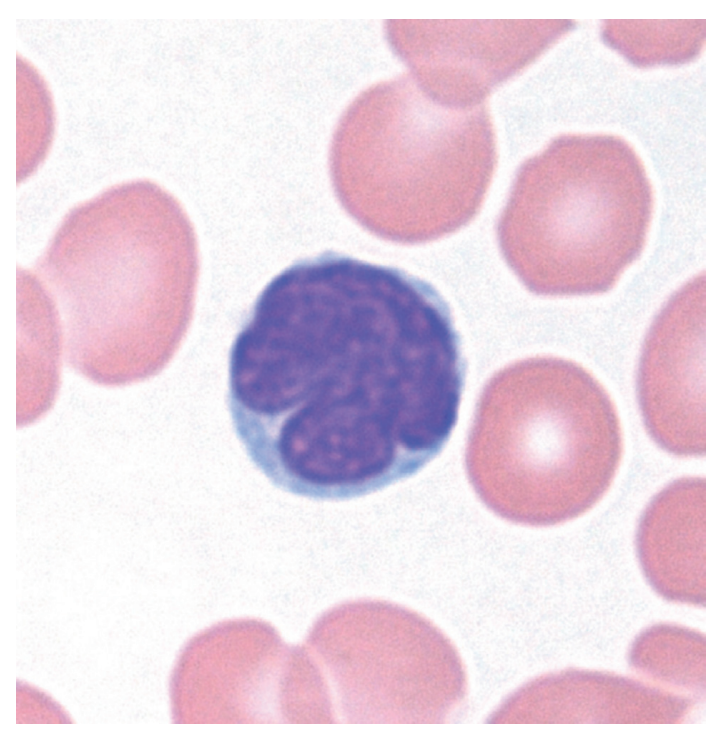

Figure 2: May-Giemsa staining of a blood smear showing abnormal cells with cerebriform nuclei $(\times 1,000)$.

virus type 1 was negative. Computed tomography revealed no lymphadenopathy or hepatosplenomegaly. Skin biopsy specimens from a tumor on the left arm showed the infiltration of abnormal lymphocytes with medium- to largesized nuclei containing convolutions in the superficial dermis (Figure 3). Immunohistochemical staining of skin biopsy specimens revealed abnormal lymphocytes expressing $\mathrm{CD} 3$ and $\mathrm{CD} 4$, but not $\mathrm{CD} 7, \mathrm{CD} 8, \mathrm{CD} 20$, or CD30. Despite approximately $30 \%$ of leukocytes in $\mathrm{PB}$ being morphologically abnormal, a small percentage of $\mathrm{PB}$ cells expressed $\mathrm{CD} 4$, and the $\mathrm{CD} 4$ : $\mathrm{CD} 8$ ratio analyzed by conventional two-color flow cytometry was 1.7.

Next, we performed a detailed phenotypical analysis by multicolor flow cytometry using a BD LSRFortessa ${ }^{\mathrm{TM}}$ cell analyzer (BD Biosciences, Franklin Lakes, NJ, USA). Among $\mathrm{CD}^{+} \mathrm{T}$ cells, $84.0 \%$ were $\mathrm{CD}^{-} \mathrm{CD}^{-}, 10.8 \%$ were $\mathrm{CD}^{+} \mathrm{CD}^{-}$, and $4.8 \%$ were $\mathrm{CD}^{-} \mathrm{CD}^{+}$(Figure 4). $\mathrm{CD}^{+}{ }^{+} \mathrm{CD} 8^{-} \mathrm{T}$ cells expressed $\mathrm{CD} 7$ and/or $\mathrm{CD} 26$ similar to normal helper $\mathrm{T}$ cells, whereas $\mathrm{CD} 4^{-} \mathrm{CD} 8^{-} \mathrm{T}$ cells had a diminished expression of CD7 and lacked CD26 expression, consistent with the Sézary cell phenotype. T-cell receptor (TCR) $\beta$-chain gene clonality assays were performed in the $\mathrm{PB}$ and skin samples in accordance with the BIOMED-2 guidelines of polymerase chain reaction- (PCR-) based immunoglobulin/TCR clonality testing (performed by SRL, Inc., Tokyo, Japan) [5]. Both PB and skin samples showed a clonal peak in $V \beta+J \beta 1 / 2$ and $D \beta+J \beta 1 / 2$, and the size of those PCR products was completely matched between both specimens as 273 bp in $V \beta+J \beta 1 / 2$ and 296 bp in $D \beta+J \beta 1 / 2$ (Figure 5). The results suggested that tumor cells in $\mathrm{PB}$ and skin were clonally identical, consistent with the pathological definition of SS.

Based on these clinical, histopathological, immunohistochemical, and genetic features, this case was diagnosed as stage IVA1 (T4N0M0B2) SS according to the International Society for Cutaneous Lymphoma/European Organization for Research and Treatment of Cancer system. The patient was treated with bexarotene and narrow-band ultraviolet $B$ therapy, which effectively reduced the cutaneous lesions and PB involvement. The best global response of the disease was a partial response based on the proposed response criteria [6]. The patient has been under this treatment for more than 9 months.

\section{Discussion}

In SS, the aberrant loss of T-cell antigens is frequently observed. The loss of CD7 and/or CD26 on neoplastic T cells is sensitive and highly specific for SS [7]. The slightly dim expression of CD4 on Sézary cells was reported in a case series [3]; however, CD4 ${ }^{-}$Sézary cells have rarely been described. A previous study reported a case of SS where $66 \%$ of the $\mathrm{CD}^{+}$fraction was $\mathrm{CD} 4^{-} \mathrm{CD}^{-}$Sézary cells [3]. Unlike our case, the Sézary cells expressed CD7 and partially lacked CD26. Because the criteria for blood involvement including an absolute Sézary cell count $\geq 1,000$ / $\mu \mathrm{L}$ and a CD 4 : $\mathrm{CD} 8$ ratio of $\geq 10$ are greatly affected in cases where CD4 molecules are lost in the $\mathrm{PB}$, it is difficult to diagnose SS using conventional flow cytometry. In such cases, the analysis of Sézary cells using multicolor flow cytometry is essential. Intriguingly, our case showed typical $\mathrm{CD} 4^{+} \mathrm{CD} 8^{-} \mathrm{CD}^{-}$neoplastic cell invasion of the skin even though Sézary cells in PB lacked CD4. In addition, the results of PCR-based TCR $\beta$-chain gene rearrangement analyses suggested that tumor cells in skin and $\mathrm{PB}$ were clonally identical. Based on these findings, we were able to make a reliable diagnosis.

SS is an aggressive disease, with a 5 -year overall survival rate of less than $40 \%[1,8]$. Combination therapies with skindirected and systemic therapies have been suggested as treatment regimens. We selected narrow-band ultraviolet $B$ therapy as a skin-directed therapy and bexarotene, an oral retinoid, as systemic therapy. Although the patient responded well to the treatments, the potential relationship between the $\mathrm{CD} 4^{-} \mathrm{CD} 8^{-}$phenotype and a good response to the treatment is unclear because of the scarcity of the disease. In mycosis fungoides, another subtype of cutaneous T-cell lymphoma, it was reported that patients with $\mathrm{CD} 4^{-} \mathrm{CD} 8^{-}$ 

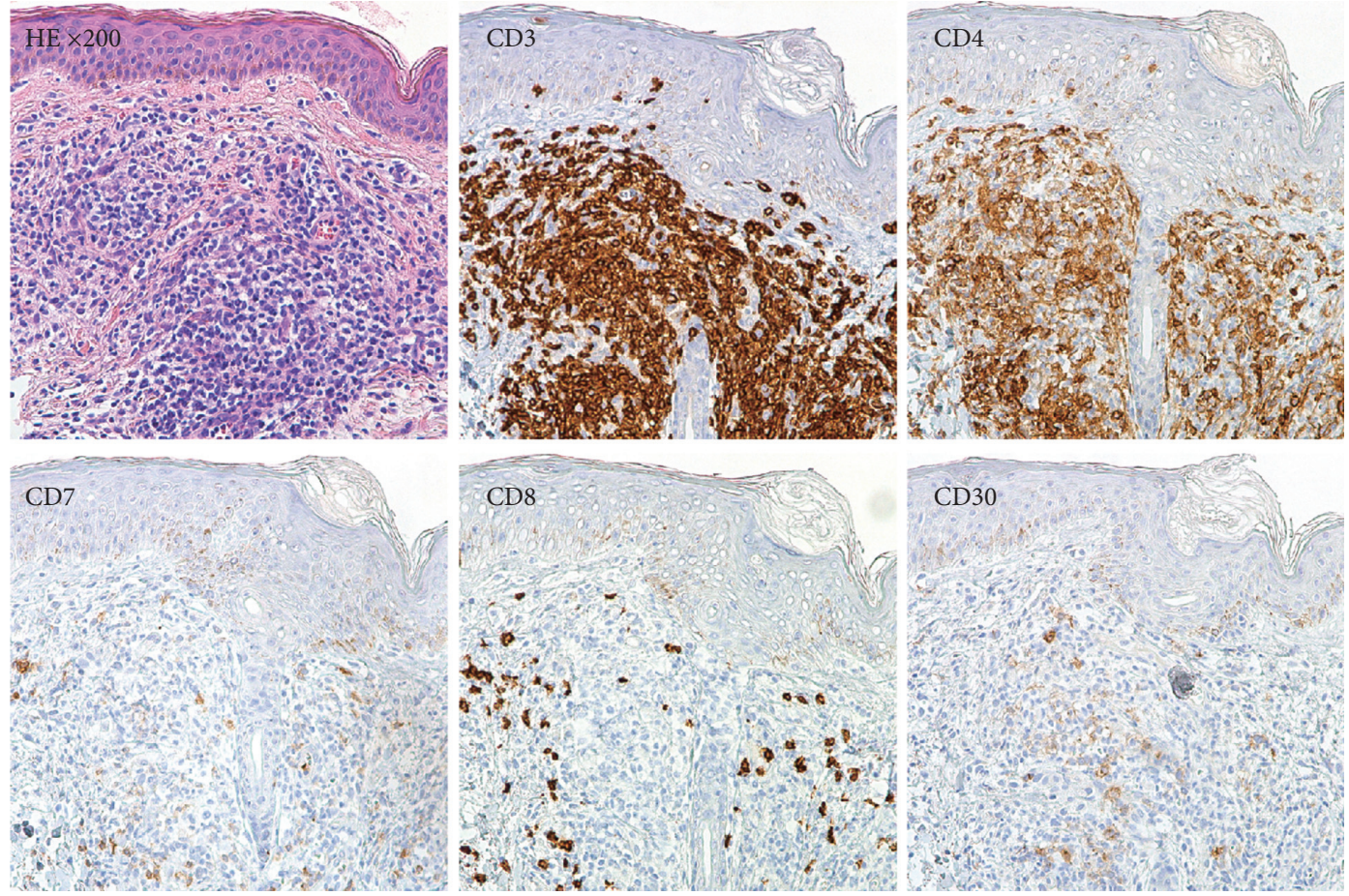

FIGURE 3: Hematoxylin-eosin (HE) staining and immunohistochemical staining of skin biopsy specimens $(\times 200)$. HE staining shows the infiltration of abnormal lymphocytes in the superficial dermis (upper left). Immunohistochemical staining shows abnormal lymphocytes are positive for CD3 (upper middle) and CD4 (upper right), but negative for CD7 (lower left), CD8 (lower middle), and CD30 (lower right).
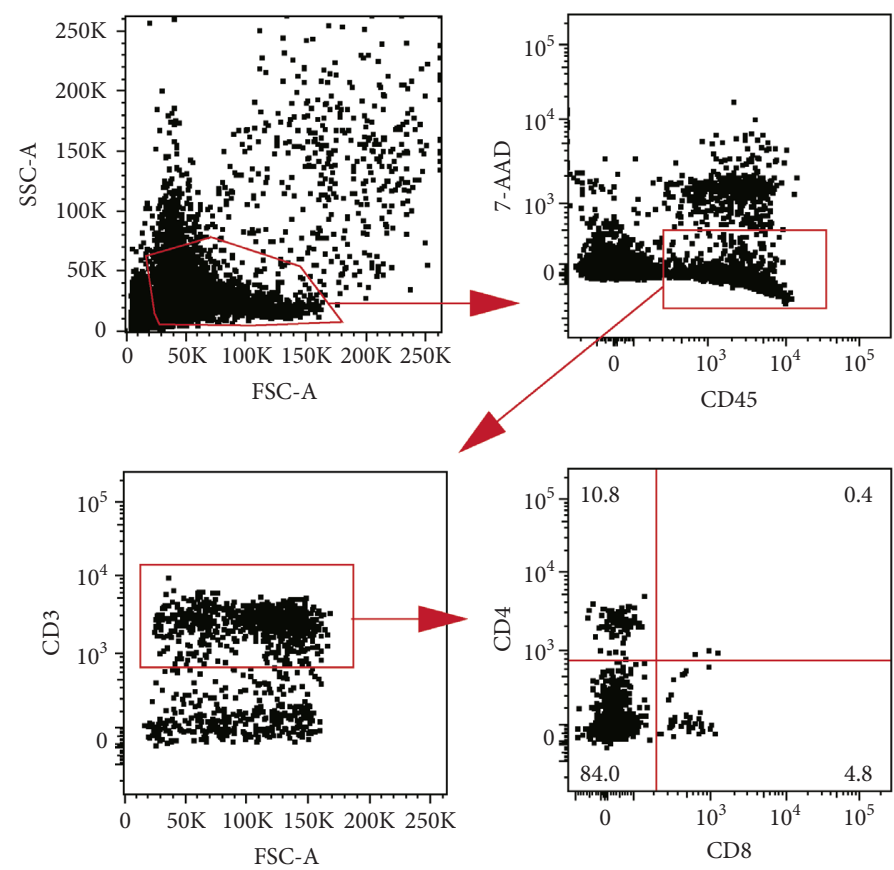

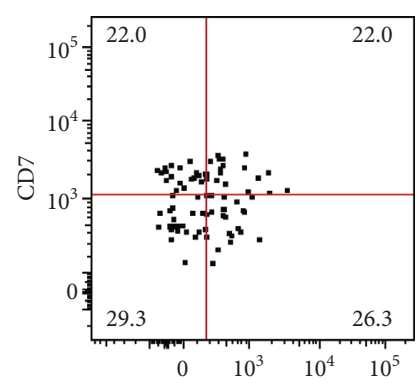

$\mathrm{CD} 4^{+} \mathrm{CD} 8$

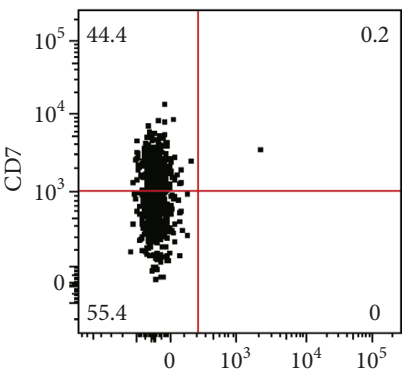

$\mathrm{CD} 4^{-} \mathrm{CD} 8$

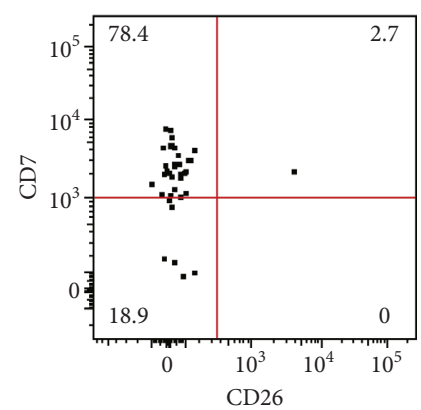

FIGURE 4: Results of multicolor flow cytometry of PB cells. After discriminating for dead cells and CD45 cells, the remaining cells were gated on $\mathrm{CD}^{+}$, and then three T-lymphocyte fractions, $\mathrm{CD} 4^{+} \mathrm{CD}^{-}, \mathrm{CD} 4^{-} \mathrm{CD} 8^{-}$, and $\mathrm{CD} 4^{-} \mathrm{CD} 8^{+}$, were analyzed for $\mathrm{CD} 7$ and $\mathrm{CD} 26$ expression. Percentages of each cell fraction are indicated in the plot areas. Abbreviations: FSC-A, forward scatter area; SSC-A, side scatter area; 7-AAD, 7-aminoactinomycin D. 
Peripheral blood

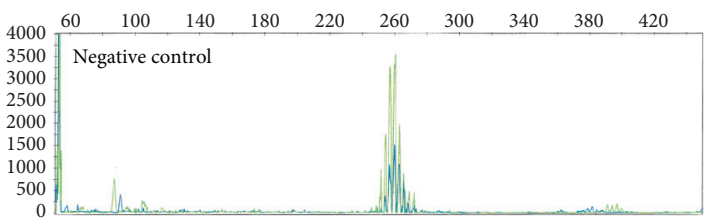

$V \beta+\mathrm{J} \beta 1 / 2$

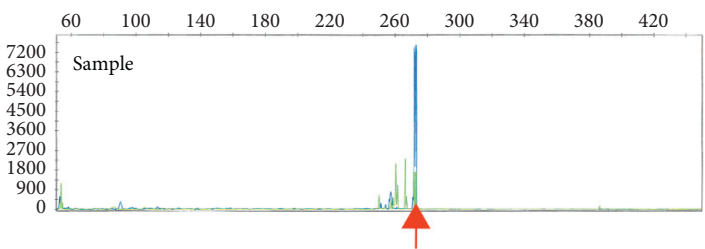

(a)

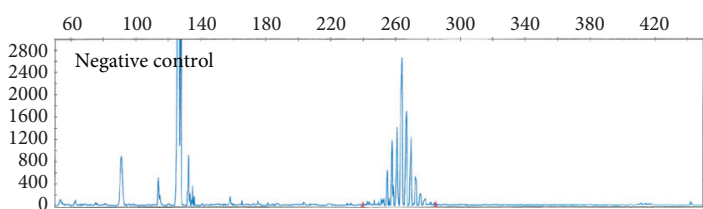

$V \beta+\mathrm{J} \beta 2$
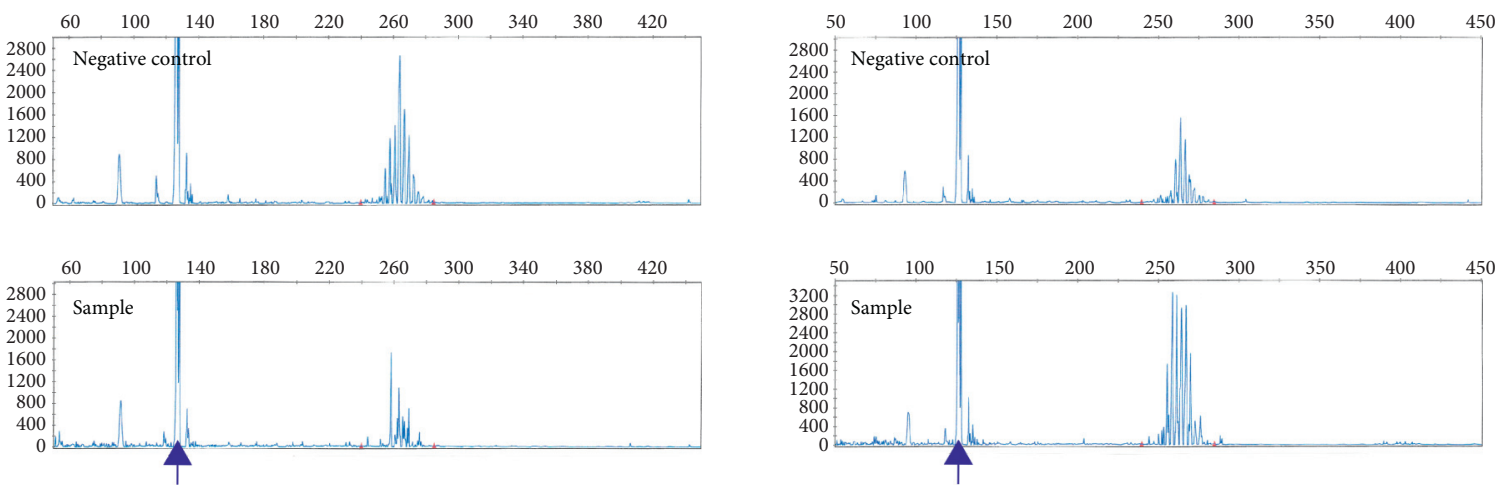

(b)

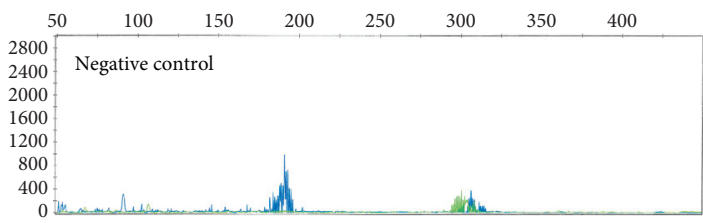

$D \beta+\mathrm{J} \beta 1 / 2$
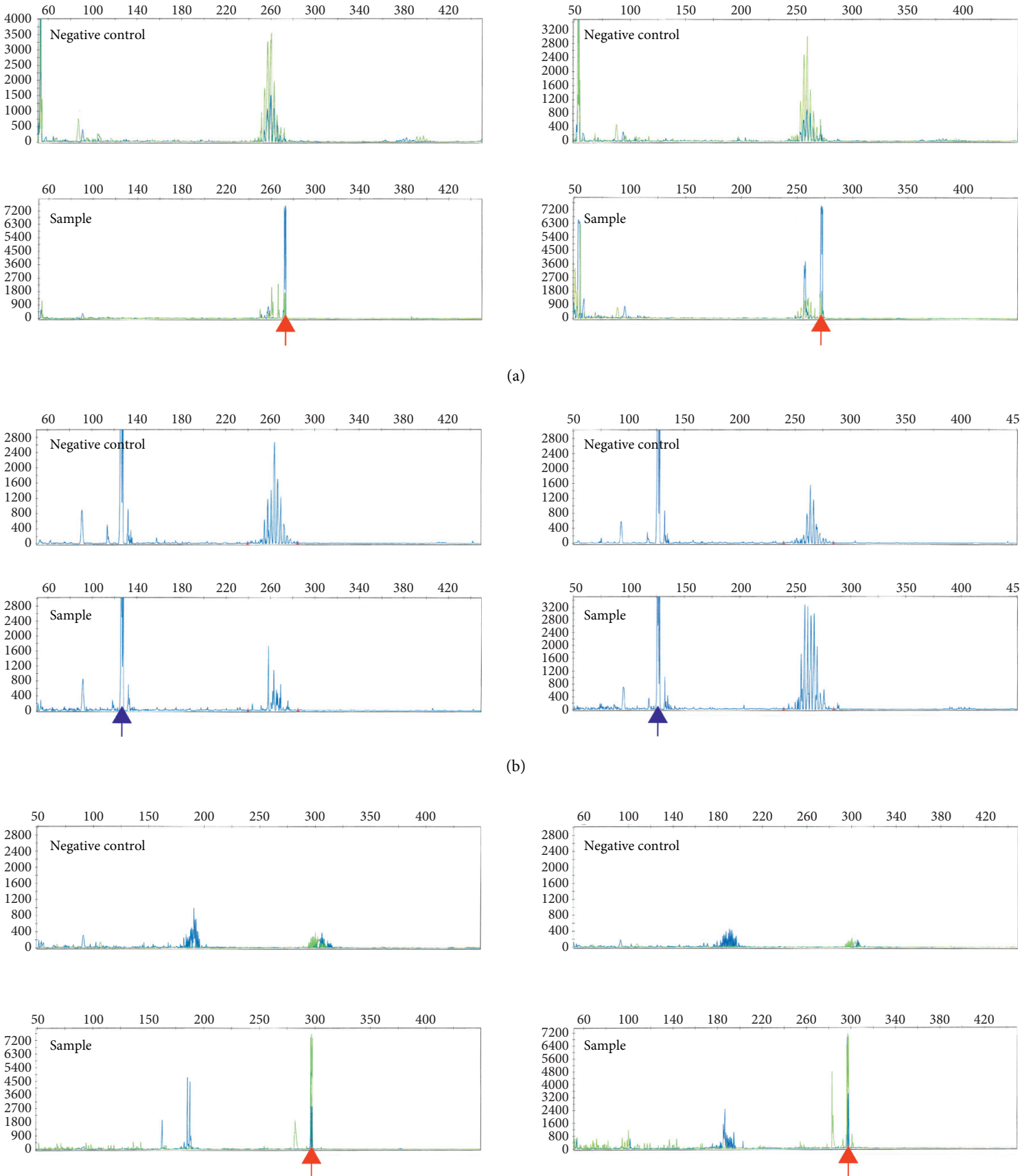

(c)

FIGURE 5: Results of TCR $\beta$-chain gene clonality assays. PCR products were produced and analyzed in accordance with the BIOMED-2 guidelines. The results of capillary electrophoresis of PCR products derived from PB (left) and skin (right) samples are shown. (a), (b), and (c) indicate the data of $V \beta+J \beta 1 / 2, V \beta+J \beta 2$, and $D \beta+J \beta 1 / 2$, respectively. In each figure, an upper figure shows data from negative control and a lower shows data from sample. The vertical line shows fluorescence intensity, the horizontal line shows fragment size, red arrows show clonal peak, and blue arrows show non-specific peak. 
tumor cells had an indolent clinical course typical of patients harboring $\mathrm{CD}^{+}$tumor cells [9].

In conclusion, $\mathrm{CD}^{-} \mathrm{CD}^{-} \mathrm{SS}$ is a rare immunophenotype of SS. Analysis by multicolor flow cytometry was essential to diagnose the disease and evaluate the tumor burden. Further studies are needed to clarify the pathogenesis and prognosis of $\mathrm{CD}^{-} \mathrm{CD}^{-} \mathrm{SS}$.

\section{Conflicts of Interest}

The authors declare that there are no conflicts of interest regarding the publication of this article.

\section{Acknowledgments}

We thank J. Ludovic Croxford, PhD, from Edanz Group (https://en-author-services.edanz.com/ac) for editing a draft of this manuscript.

\section{References}

[1] R. Willemze, L. Cerroni, W. Kempf et al., "The 2018 update of the WHO-EORTC classification for primary cutaneous lymphomas," Blood, vol. 133, no. 16, pp. 1703-1714, 2019.

[2] M. Novelli, P. Fava, C. Sarda et al., "Blood flow cytometry in Sézary syndrome," American Journal of Clinical Pathology, vol. 143, no. 1, pp. 57-69, 2015.

[3] P. Horna, S. A. Wang, K. L. Wolniak et al., "Flow cytometric evaluation of peripheral blood for suspected Sézary syndrome or mycosis fungoides: International guidelines for assay characteristics," Cytometry Part B: Clinical Cytometry, 2020.

[4] A. C. Hristov, E. C. Vonderheid, and M. J. Borowitz, "Simplified flow cytometric assessment in mycosis fungoides and Sézary syndrome," American Journal of Clinical Pathology, vol. 136, no. 6, pp. 944-953, 2011.

[5] A. W. Langerak, P. J. T. A. Groenen, M. Brüggemann et al., "EuroClonality/BIOMED-2 guidelines for interpretation and reporting of Ig/TCR clonality testing in suspected lymphoproliferations," Leukemia, vol. 26, no. 10, pp. 2159-2171, 2012.

[6] E. A. Olsen, S. Whittaker, Y. H. Kim et al., "Clinical end points and response criteria in mycosis fungoides and Sézary syndrome: a consensus statement of the international society for cutaneous lymphomas, the United States cutaneous lymphoma consortium, and the cutaneous lymphoma task force of the European organisation for Research and treatment of cancer," Journal of Clinical Oncology, vol. 29, no. 18, pp. 2598-2607, 2011.

[7] S. E. Boonk, W. H. Zoutman, A. Marie-Cardine et al., "Evaluation of immunophenotypic and molecular biomarkers for Sézary syndrome using standard operating procedures: a multicenter study of 59 patients," Journal of Investigative Dermatology, vol. 136, no. 7, pp. 1364-1372, 2016.

[8] J. J. Scarisbrick, H. M. Prince, M. H. Vermeer et al., "Cutaneous lymphoma international consortium study of outcome in advanced stages of mycosis fungoides and Sézary syndrome: effect of specific prognostic markers on survival and development of a prognostic model," Journal of Clinical Oncology, vol. 33, pp. 3766-3773, 2015.

[9] E. Hodak, M. David, L. Maron, A. Aviram, E. Kaganovsky, and M. Feinmesser, "CD4/CD8 double-negative epidermotropic cutaneous T-cell lymphoma: an immunohistochemical variant of mycosis fungoides," Journal of the American Academy of Dermatology, vol. 55, no. 2, pp. 276-284, 2006. 